\title{
Analysis of bacterial growth at various distances from an antimicrobial surface
}

\author{
Shohei Nunose ${ }^{1}$, Rie Iwai ${ }^{2}$, Shujiro Okuda ${ }^{1}$, Yuki Tsuchiya ${ }^{1}$, Hisao Morisaki ${ }^{1 *}$ \\ ${ }^{1}$ College of Life Sciences, Ritsumeikan University, Kusatsu, Japan \\ ${ }^{2}$ Faculty of Science and Engineering, Ritsumeikan University, Kusatsu, Japan \\ Email: ${ }^{*}$ morisaki@sk.ritsumei.ac.jp
}

Received 22 January 2013; revised 7 March 2013; accepted 10 April 2013

Copyright (C) 2013 Shohei Nunose et al. This is an open access article distributed under the Creative Commons Attribution License, which permits unrestricted use, distribution, and reproduction in any medium, provided the original work is properly cited.

\begin{abstract}
Antimicrobial materials have been used in various environments. However, the activity of cells at a distance from the antimicrobial materials has not been elucidated. In the present study, the cell growth of Escherichia coli NBRC 3972 was observed at different distances $(0$ - $300 \mu \mathrm{m})$ from the antimicrobial surface under various nutrient concentrations, from full strength nutrient broth (NB) to $1 / 40 \mathrm{NB}$. Under higher nutrient concentrations, NB and 1/2 NB, no antimicrobial effect on cell growth was observed at any distance from the surface. Under lower nutrient concentrations, 1/10 NB and 1/40 NB, the growth of cells directly contacting the antimicrobial surface (at $0 \mu \mathrm{m}$ from the surface) was blocked immediately after inoculation on the surface. However, at distances of 100 $300 \mathrm{\mu m}$ from the surface, the cells grew normally for a while, and then stopped the growth; earlier growth discontinuation was observed for cells closer to the surface. It was suggested that the antimicrobial agent (silver ions) is released from the antimicrobial surface into the medium and that the diffusion of the silver ions may influence the lag in the antimicrobial effects observed at distances away from the antimicrobial surface. The present study reveals the possibility that antimicrobial activity in the environments where the antimicrobial material is used depends on the distance from the surface and the surrounding nutrient concentrations.
\end{abstract}

Keywords: Antimicrobial Surface; Escherichia coli; Microculture; Biofilm

\section{INTRODUCTION}

Antimicrobial materials have been used in various con-

"Corresponding author. texts worldwide [1-6]. However, concerns are being raised regarding the overuse of antimicrobial materials and the consequent emergence of bacterial resistance [7-10]. The range of bacterial responses to antimicrobial materials is extensive. Thus, precise evaluation of the antimicrobial activity of various antimicrobial materials is important for their further application and to prevent problems caused by the improper utilization of these materials.

The activity of antimicrobial materials is conventionally estimated by using an indirect method, in accordance with ISO 22196 guidelines (JIS Z2801; 2000) [11]. This method has been used worldwide as an index for estimating surface antimicrobial activity. Recently, we have successfully observed cell growth on antimicrobial surfaces directly by using a microscope, and reported that the antimicrobial material showed higher activity to bacterial cells on the surface at the diluted nutrient concentration that is similar with that in domestic environments [12].

In environments, bacteria often form biofilms on the surface of substrates and show resistances to antimicrobial agents $[7,8]$. Previously, we have clarified that the nutrient ion $\left(\mathrm{NH}_{4}^{+}, \mathrm{NO}_{3}^{-}, \mathrm{NO}_{2}^{-}, \mathrm{PO}_{4}^{3-}\right)$ concentrations in biofilms were much higher than those in the surrounding environment [13]. Thus, when biofilms are formed, bacteria inside biofilms are exposed to higher nutrient concentrations than those in the surrounding environment. In addition, bacteria in biofilms do not directly attach to surfaces; bacteria exist at various distances from the surface because of the biofilm thickness [14]. These high nutrient concentrations and distances from the surface may affect the antimicrobial activity and relate with the resistances of bacteria in biofilms against antimicrobial agents. Therefore, to understand and evaluate an antimicrobial activity in actual environments, the analysis of antimicrobial activity at various distances from the antimicrobial surface and in various nutrient conditions is 
necessary.

In the present study, the growth of Escherichia coli NBRC 3972 on antimicrobial and non-antimicrobial materials was investigated at various distances from the surface and at various nutrient concentrations, by modifying the method used in our previous study [12]: we directly observed cell growth at different distances from the surface within a medium using a microscope. Using this method, antibiotic activity in relation to the distance from the surface could be evaluated quantitatively and precisely. The present study revealed that the antimicrobial effect on cells at a distance from the antimicrobial surface is delayed in relation to the distance from the surface. The findings of this study will deepen our understanding of the hitherto controversial mechanism underlying the antimicrobial activity of certain materials.

\section{MATERIALS AND METHODS}

\subsection{Culture and Preparation of Bacterial Cells}

In the present study, the strain E. coli NBRC 3972 (isolated from human feces [15]) obtained from the Biological Resource Center of the National Institute of Technology and Evaluation in Japan was used. This strain was recommended in ISO 22196 for the evaluation of antimicrobial activity and was used in our previous study [12]. The cells were cultured in nutrient broth (NB) medium at $33^{\circ} \mathrm{C}$ with shaking $(100 \mathrm{rpm})$ until the stationary phase $(24 \mathrm{~h})$. The cultured cells were then used for microculture.

\subsection{Microculture of Bacterial Cells at Different Distances from Antimicrobial and Non-Antimicrobial Surfaces}

The microculture method used in the previous study [12] was modified to observe cell growth at different distances from the antimicrobial surface, as shown in Figure 1. One hundred microliters of cell suspension was mixed with $10 \mathrm{~mL}$ of $\mathrm{NB}$ or diluted $\mathrm{NB}(1 / 2,1 / 10$, and $1 / 40)$ agar medium $(1.5 \%)$ at $47^{\circ} \mathrm{C}$, and $120 \mu \mathrm{L}$ of the agar containing cells $\left(10^{8}\right.$ cells $\left./ \mathrm{mL}\right)$ was used for making a small agar block $(14 \times 14 \times 0.4 \mathrm{~mm})$. Immediately, the agar block was placed gently, face down on the antimicrobial (GPPS 1.0\%; high-impact polystyrene plate with $1.0 \%$ of the antimicrobial agent Novaron AG1100; Toagosei, Tokyo, Japan) or non-antimicrobial material (GPPS BL; the same material as the antimicrobial material without the antimicrobial agent). A cover glass $(18 \times$ $18 \mathrm{~mm}$; thickness, 0.12 - $0.17 \mathrm{~mm}$; Matsunami, Tokyo, Japan) was placed over the agar. The margins of the prepared specimens were sealed with a sealant to prevent desiccation. The specimens were kept on the stage of a microscope (BX50; Olympus, Tokyo, Japan), and bacterial growth was directly observed. During the experi- ment, an almost constant temperature of $26^{\circ} \mathrm{C}$ was maintained.

When bacterial cells grow in a medium on non-antimicrobial or antimicrobial material, they increase in cell number over time and form microscale colonies. We observed the microscale colonies at a vertical distance of 0 , 100,200 , and $300 \mu \mathrm{m}$ from the surface through the microscope in 2 fields of view (width of 1 field, $160 \times 220$ $\mu \mathrm{m})$ and photographed the colonies intermittently at 30 min intervals. The distances from the solid surface were adjusted using the scale attached to the adjustment handle of the microscope. In the previous study, the colony area was estimated for growth rate constants. On the other hand, in the present study, we determined the number of cells per micro-colony for more precise measurements.

\section{RESULTS AND DISCUSSION}

In the present study, the growth of E. coli NBRC 3972 at different distances $(0,100,200$, and $300 \mu \mathrm{m})$ from antimicrobial and non-antimicrobial surfaces was directly observed under a microscope using the modified microculture method (Figure 1). An example of the growth curve of E. coli observed using the above-mentioned method is shown in Figure 2. In the present study, the number of cells per colony was determined during the growth phase to estimate the growth rate constants of the cells. After the growth had stopped, the number of cells per colony was determined and the growth termination time was investigated.

\subsection{Growth Rate Constants at Different Vertical Distances from Antimicrobial and Non-Antimicrobial Surfaces}

The growth rate constants for E. coli in full-strength NB

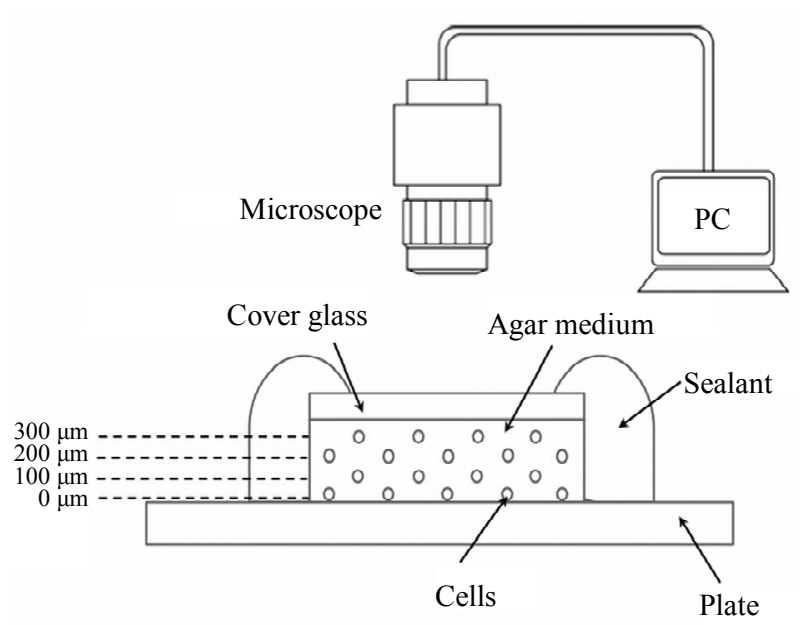

Figure 1. Schematic illustration of the modified microculture method. The method of Yamada et al. (2010) was slightly modified. 


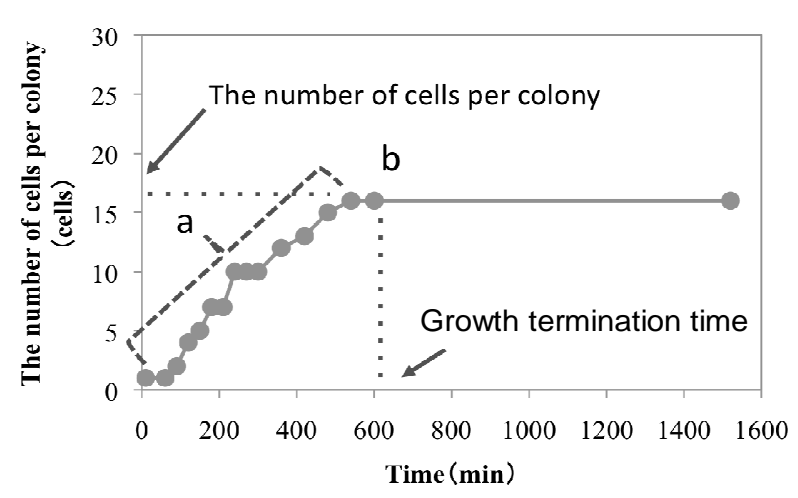

Figure 2. Growth curve of Escherichia coli NBRC 3972 at a distance of $100 \mu \mathrm{m}$ from the non-antimicrobial (GPPS BL) surface in the full-strength nutrient broth (NB) medium. During the growth phase (denoted by "a"), the number of cells per colony was determined to estimate the growth rate constant. After the growth phase (denoted by "b"), the number of cells per colony and the growth termination time was measured.

agar medium on the non-antimicrobial surface (GPPS BL) were similar for all the different distances from the surface (Figure 3). This was also the case under other nutrient concentrations, from 2-fold-diluted NB (1/2 NB) to 40-fold-diluted NB (1/40 NB) (Figure 3). Moreover, the growth rate constants were similar for all nutrient concentrations. These results indicate that the bacterial growth rate on non-antimicrobial material is not affected by the
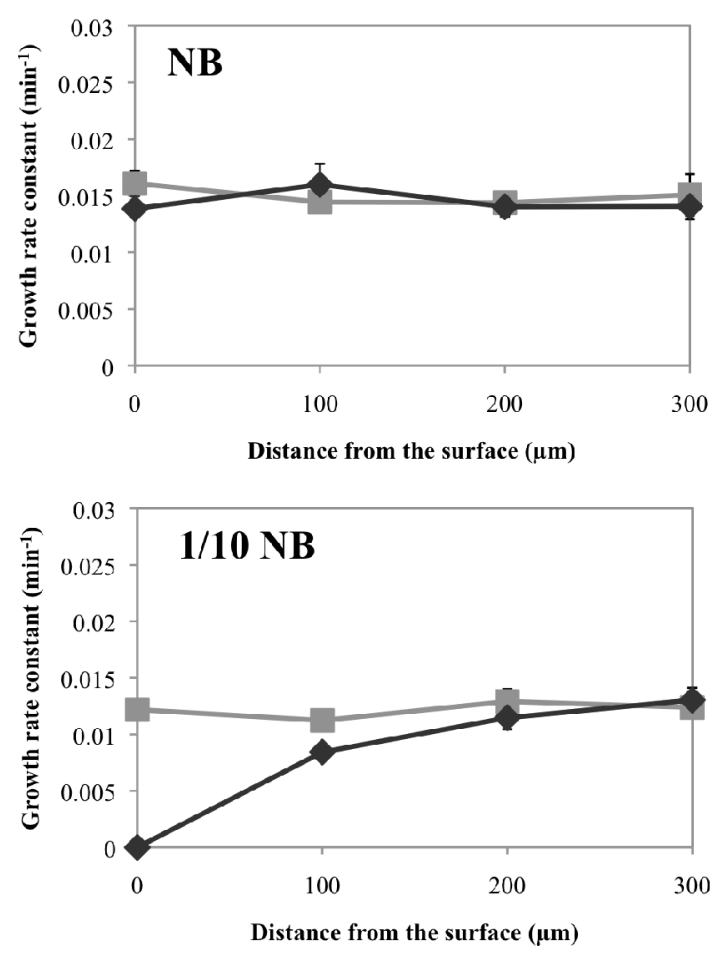

distance from the surface or the nutrient concentration surrounding the bacterial cells, and that diluted nutrient concentrations (even at 1/40 NB) were sufficient for the cells to show the same growth rates as those observed at higher nutrient concentrations.

On the antimicrobial material (GPPS 1.0\%), the growth rate constants for $E$. coli were similar to those observed on the non-antimicrobial material at every distance for NB and 1/2 NB (Figure 3). At lower nutrient concentrations, namely, $1 / 10 \mathrm{NB}$ and $1 / 40 \mathrm{NB}$, the growth rate constants for distances of $100-300 \mu \mathrm{m}$ from the surface were similar to those on the non-antimicrobial material, whereas the growth rate constants on the surface $(0$ $\mu \mathrm{m})$ was $0 \mathrm{~min}^{-1}$; no cell growth was observed (Figure 3).

In the previous study, we found that antimicrobial activity on the surface was evident when cells were cultured under low nutrient concentrations, and we deduced that antimicrobial materials retard the nutrient uptake or nutrient utilization efficiency of cells or block the initiation of the cell cycle [12]. The same appears to be true for the antimicrobial surface used in the present study, though the nutrient concentrations used were somewhat different. On the other hand, the growth of cells only at slightly apart from the antimicrobial surface seems to not be affected by the antimicrobial material even at low nutrient concentrations.
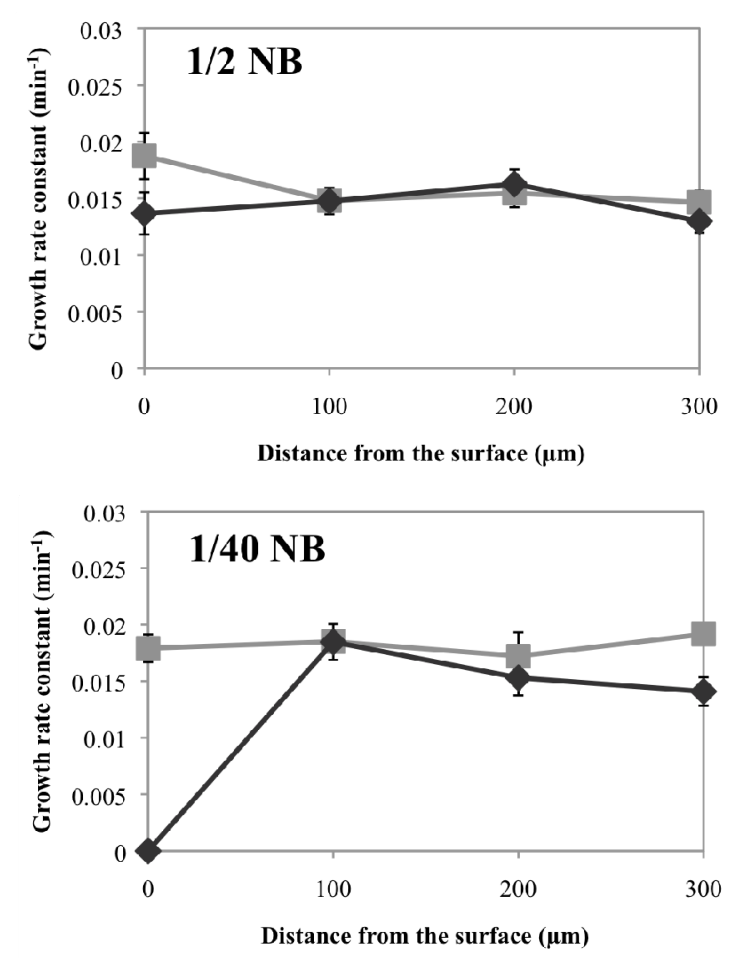

Figure 3. Growth rate constants for $E$. coli at different vertical distances $(0-300 \mu \mathrm{m})$ from the antimicrobial (GPPS $1.0 \%$; $)$ and non-antimicrobial (GPPS BL; $\square$ ) surfaces in media of varying concentrations (from full-strength NB to $1 / 40 \mathrm{NB})$. The average values are indicated with standard errors $(n=9-10)$. 


\subsection{Number of Cells per Colony and Growth Termination Time at Various Distances from Antimicrobial and Non-Antimicrobial Surfaces}

The number of cells per colony after the cessation of cell growth at different distances from the antimicrobial and non-antimicrobial surfaces was investigated. E. coli colonies incubated with NB on the antimicrobial material contained a similar number of cells as those on the nonantimicrobial material at all distances (Figure 4). However, at lower nutrient concentrations, the number of cells on the antimicrobial material was lower than that on the non-antimicrobial material. This observation was most prominent at smaller distances from the surface, as shown in Figure 4.

E. coli colonies start to grow from a single cell, with the number of cells per colony increasing until the cessation of growth. Therefore, the number of cells per colony after the cessation of growth depends on the growth rate and the growth period of the cells. The growth rate constants were similar between the antimicrobial and non-antimicrobial material, though no cell growth was observed at the antimicrobial surface $(0 \mu \mathrm{m})$, as shown in Figure 3. Thus, the colony size should be mainly determined by the growth-continuing period; shorter growth period leads to lesser number of cells per colony. This finding was apparent at low nutrient concentrations such
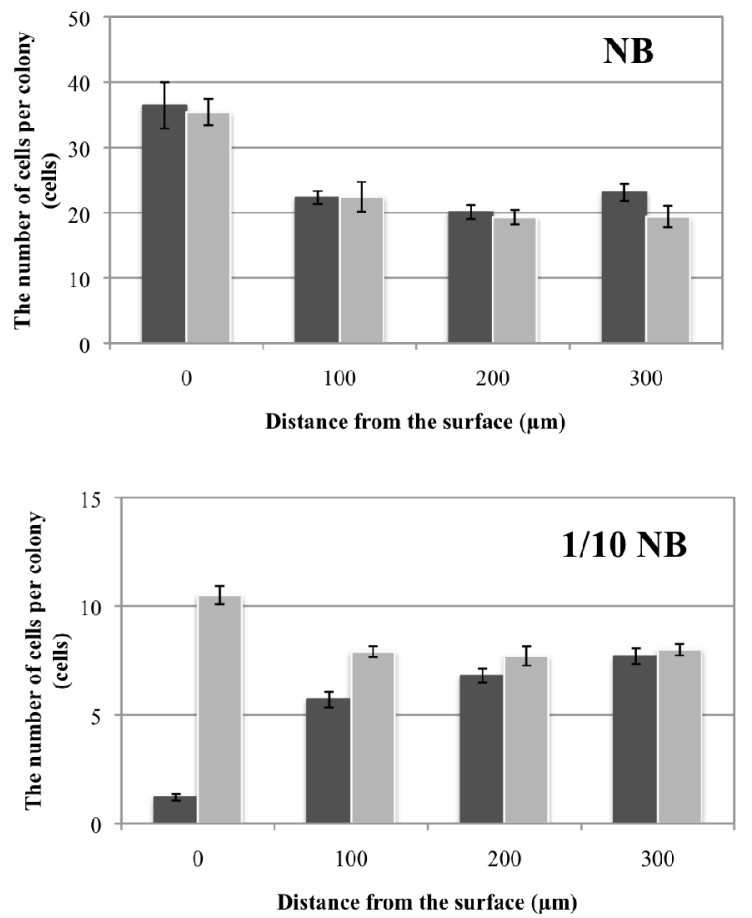

as 1/10 NB and 1/40 NB (see Figures 5 and S1). Therefore, it was suggested that the less number of cells per colony in relation to the distance from the antimicrobial surface (Figure 4) was greatly related to the shorter growth period until growth termination, even if the cell growth was initiated at a normal rate.

On the non-antimicrobial and antimicrobial surfaces $(0$ $\mu \mathrm{m})$ under NB conditions and on the non-antimicrobial surface $(0 \mu \mathrm{m})$ under $1 / 2 \mathrm{NB}$ conditions, the number of cells per colony was greater than that at the other distances under the same nutrient concentrations. Although the growth rate constants under these conditions were similar to those at other distances, the growth periods were longer than those at the other distances (more than 1440 min). On these surfaces, the colonies spread two-dimensionally along the surface, whereas the colonies at other distances enlarged three-dimensionally. In two-dimensionally spreading colonies, more cells may be able to contact the surrounding nutrients than those in three-dimensionally enlarging colonies, leading to a longer period of nutrient uptake and resulting in colonies with a greater number of cells.

\subsection{Mechanism Underlying Different Antimicrobial Effects Depending on the Distance from the Antimicrobial Surface}

The antimicrobial material used in the present study
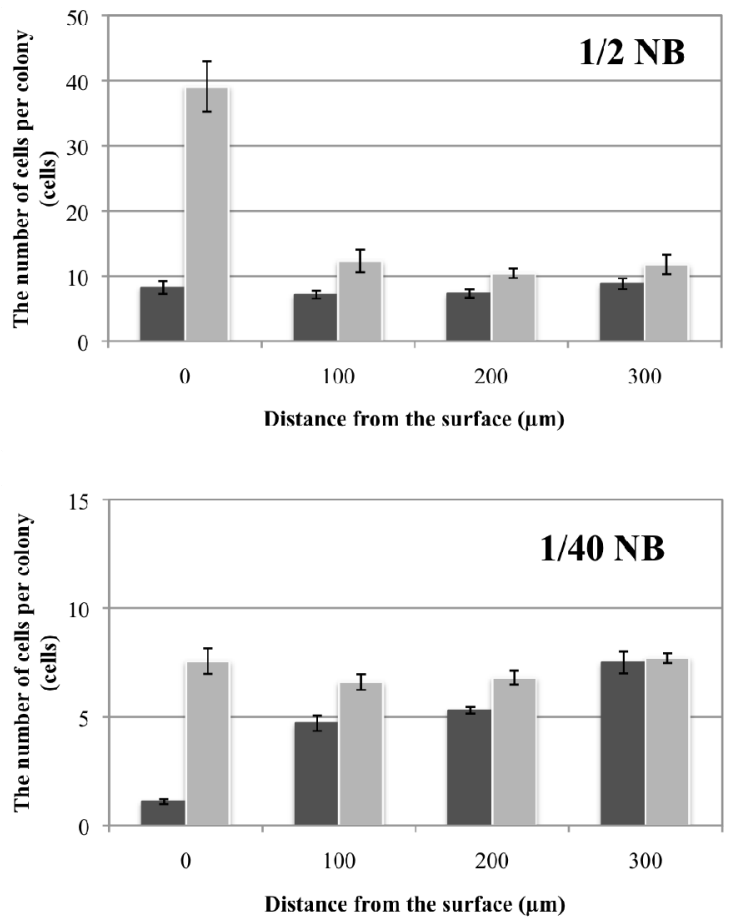

Figure 4. The number of cells per colony after microculture of $E$. coli at different distances from the antimicrobial (GPPS 1.0\%; $\mathbf{0}$ ) and non-antimicrobial (GPPS BL; $\square$ ) surfaces in media of varying concentrations. Bars indicate standard errors $(n=9-10)$. 

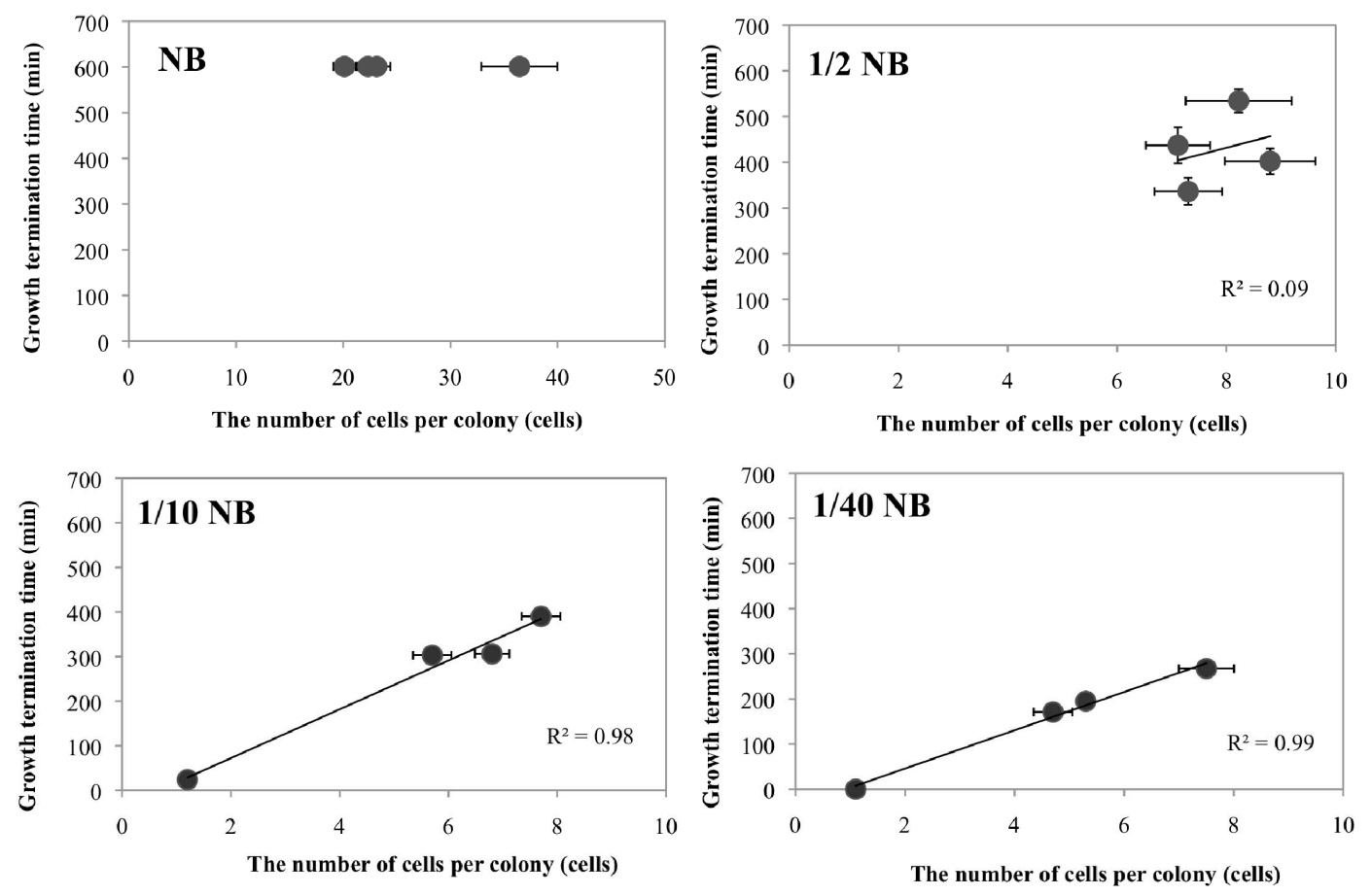

Figure 5. The relationship between the number of cells per colony and growth termination time at different distances from the antimicrobial surface (GPPS 1.0\%) in media of varying concentrations (full-strength NB to $1 / 40 \mathrm{NB})$. The solid line represents the least-squares fit of the data. Bars indicate standard errors $(\mathrm{n}=9-10)$. The data shown in Figures $\mathbf{4}$ and $\mathbf{S 1}$ were used for the number of cells per colony and growth termination time, respectively. The E. coli cells in NB medium grew for such a long time that the growth termination time exceeded $600 \mathrm{~min}$. So, for the case of $\mathrm{NB}$, the growth termination times were plotted as $600 \mathrm{~min}$ in the figure.

contained an inorganic antimicrobial agent (Novaron AG1100) composed of silver-based ion exchangers in hexagonal phosphate zirconium and an organic material, polystyrene. Novaron is presumed to exert its antimicrobial effect through silver ions released from the material and/or activated oxygen generated from water in the presence of Novaron and light, according to the manufacturer's description (US Food and Drug Administration approved). In a preliminary experiment to avoid the light effect, we performed a microculture experiment under constant dark conditions and compared the final number of cells per colony to those of the present study. The antimicrobial effect was the same as that in the present study (data not shown). Thus, the silver ions seem to be the main factor generating the antimicrobial effect in our experiments. The release rate of silver ions from the material, although quite small, has been reported to be enhanced in the presence of amino acids and proteins [16]. Silver ions released from the material seem to have diffused into the nutrient agar during the incubation period in the present study. In this case, the diffusion of silver ions can have different antimicrobial effects depending on the distance from the surface, because the silver ions take time to diffuse and reach the cells in areas distant from the surface of the antimicrobial material. Thus, at lower nutrient concentrations ( $1 / 10$ and $1 / 40 \mathrm{NB})$, the silver ions may get released from the antimicrobial surface just after incubation and block cell growth at the antimicrobial surface $(0 \mu \mathrm{m})$ from the beginning of the incubation, resulting in the lack of cell growth on the surface. In comparison, at $100-300 \mu \mathrm{m}$ from the surface, the cells can grow at the same rate as those on the non-antimicrobial surface until the silver ions have reached the cells, where after cell growth is arrested, resulting in a lesser number of cells per colony due to a shorter growth period compared with that on the non-antimicrobial material. The diffusion rate of silver ions and the effective concentrations of silver ions as antimicrobial agents are further subjects to be investigated.

In the environments in which antimicrobial surfaces are used, bacteria often form biofilms on the surface. The biofilms formed on the antimicrobial surface may inhibit antimicrobial activity; this phenomenon may be due to the decrease in the susceptibility of microbes to materials loaded with antibiotics, and this decrease is caused by the production of extracellular polymeric substances [7, 8]. On the basis of the results of the present study, it may be concluded that the three-dimensional structure [14] and the higher nutrient ion concentration in biofilms [13] also weaken the antimicrobial activity in the biofilm on the 
antimicrobial surface.

\section{CONCLUSION}

The present study showed that the cell growth of E. coli NBRC 3972 directly contacting the antimicrobial surface (at $0 \mu \mathrm{m}$ from the surface) was blocked immediately after inoculation on the surface. However, the cell growth at distances of $100-300 \mu \mathrm{m}$ from the antimicrobial surface was started normally for a while, and then stopped; earlier growth termination was observed for cells closer to the surface. This delay of the growth termination was more obvious under lower nutrient concentrations ( $1 / 10$ and $1 / 40 \mathrm{NB})$. To our best knowledge, the present study is the first to report that the antimicrobial effect on bacterial cells depends on the distance from the antimicrobial surface. In the environments in which antimicrobial surfaces are used, the antimicrobial activity may be weakened by the formation of biofilms because of the three-dimensional structure and the high nutrient concentrations in biofilms.

\section{ACKNOWLEDGEMENTS}

This study was supported by a fund from the Society of Industrial Technology for Antimicrobial Articles, Japan. We express our appreciation to this Society for providing the antimicrobial and non-antimicrobial materials for this study.

\section{REFERENCES}

[1] Casey, A.L., Adams, D., Karpanen, T.J., Lambert, P.A., Cookson, B.D., Nightingale, P., Miruszenko, L., Shillam, R., Christian, P. and Elliott, T.S. (2009) Role of copper in reducing hospital environment contamination. Journal of Hospital Infection, 74, 72-77. doi:10.1016/j.jhin.2009.08.018

[2] Galeano, B., Korff, E. and Nicholson, W.L. (2003) Inactivation of vegetative cells, but not spores, of Bacillus anthracis, B. cereus, and B. subtilis on stainless steel surfaces coated with an antimicrobial silver- and zinc-containing zeolite formulation. Applied Environmental Microbiology, 69, 4329-4331. doi:10.1128/AEM.69.7.4329-4331.2003

[3] Leaper, D.J. (2006) Silver dressings: Their role in wound management. International Wound Journal, 3, 282-294. doi:10.1111/j.1742-481X.2006.00265.X

[4] Lellouche, J., Kahana, E., Elias, S., Gedanken, A. and Banin, E. (2009) Antibiofilm activity of nanosized magnesium fluoride. Biomaterials, 30, 5969-5978. doi:10.2147/IJN.S26770

[5] Monteiro, D.R., Gorup, L.F., Takamiya, A.S., Ruvollo-Filho, A.C., de Camargo, E.R. and Barbosa, D.B. (2009) The growing importance of materials that prevent microbial adhesion: Antimicrobial effect of medical devices containing silver. International Journal of Antimicrobial Agents, 34, 103-110. doi:10.1080/08927014.2011.599101

[6] Stevens, K.N., Crespo-Biel, O., van den Bosch, E.E., Dias, A.A., Knetsch, M.L., Aldenhoff, Y.B., van der Veen, F.H., Maessen, J.G., Stobberingh, E.E. and Koole, L.H. (2009) The relationship between the antimicrobial effect of catheter coatings containing silver nanoparticles and the coagulation of contacting blood. Biomaterials, 30, 36823690. doi:10.1016/i.biomaterials.2009.03.054

[7] Engelsman, A.F., van der Mei, H.C., Busscher, H.J. and Ploeg, R.J. (2008) Morphological aspects of surgical meshes as a risk factor for bacterial colonization. British Journal of Surgery, 95, 1051-1059. doi:10.1002/bjs.6154

[8] Neut, D., Hendriks, J.G., van Horn, J.R., van der Mei, H.C. and Busscher, H.J. (2005) Pseudomonas aeruginosa biofilm formation and slime excretion on antibioticloaded bone cement. Acta Orthopaedica, 76, 109-114. doi:10.1080/00016470510030427

[9] Percival, S.L., Bowler, P.G. and Russell, D. (2005) Bacterial resistance to silver in wound care. Journal of Hospital Infection, 60, 1-7. doi:10.1016/j.jhin.2004.11.014

[10] Silver, S., Gupta, A., Matsui, K. and Lo, J.F. (1999) Resistance to $\mathrm{Ag}(\mathrm{I})$ cations in bacteria: Environments, genes and proteins. Metal-Based Drugs, 6, 315-320. doi:10.1155/MBD.1999.315

[11] Japanese Industrial Standard Committee (2000) Antimicrobial products-test for antimicrobial activity and efficacy. Publication JIS Z 2801:2000. Japanese Standards Association, Tokyo.

[12] Yamada, H., Takahashi, N., Okuda, S., Tsuchiya Y. and Morisaki, H. (2010) Direct observation and analysis of bacterial growth on an antimicrobial surface. Applied Environmental Microbiology, 76, 5409-5414.

doi:10.1128/AEM.00576-10

[13] Tsuchiya, Y., Ikenaga, M., Kuriawan, A., Hiraki, A., Arakawa, T., Kusakabe, R. and Morisaki, H. (2009) Nutrientrich microhabitats within biofilms are synchronized with the external environment. Microbes Environment, 24, 4351. doi:10.1264/jsme2.ME08547

[14] Stewart, P.S., Murga, R., Srinivasani, R. and de Beer, D. (1995) Biofilm structural heterogeneity visualized by three microscopic methods. Water Research, 29, 2006-2009. doi:10.1016/0043-1354(94)00339-9

[15] Gunsalus, I.C. and Hand, D.B. (1941) The use of bacteria in the chemical determination of total vitamin c. Journal of Biological Chemistry, 141, 853-858.

[16] Tsubai, Y. (1997) Mechanism of exerting antimicrobial activity of inorganic antimicrobial materials. In: Oya, A., Ed., Diversifying Inorganic Antimicrobial Materials and Their Application, Industrial Publishing and Consulting, Tokyo, 61 . 


\section{Supplement}

GPPS BL
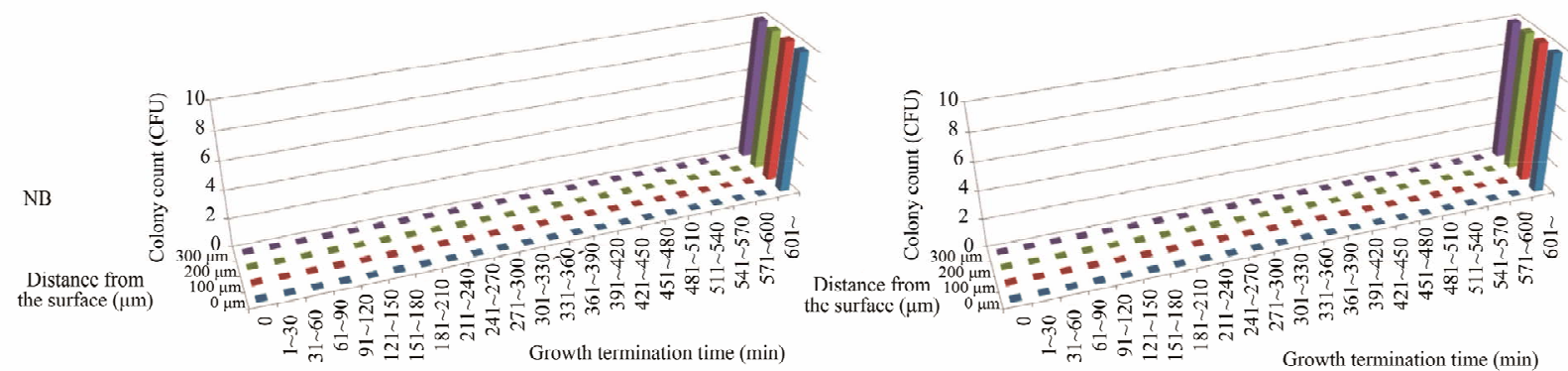

Growth termination time (min)
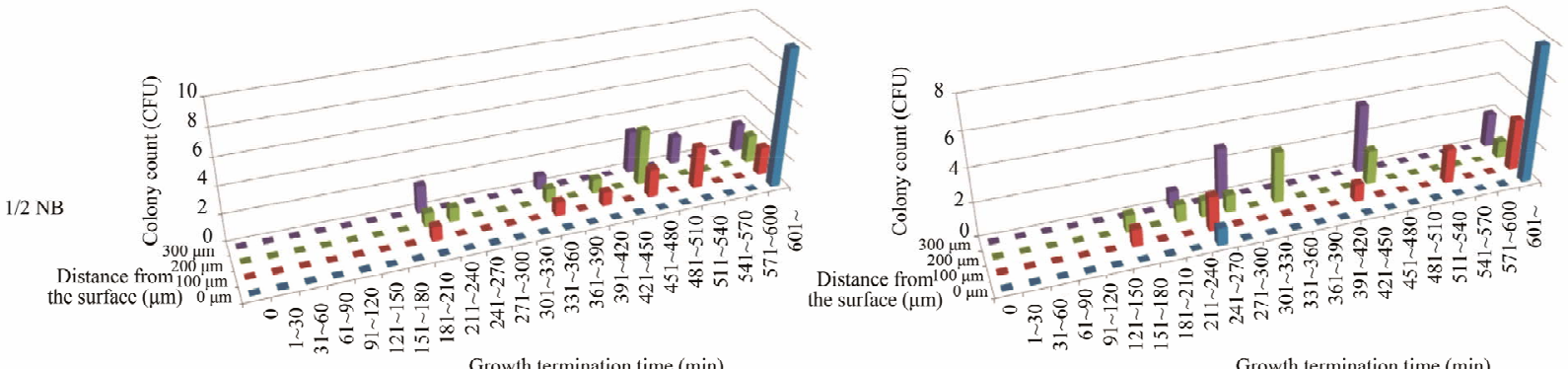

Growth temination time (min)
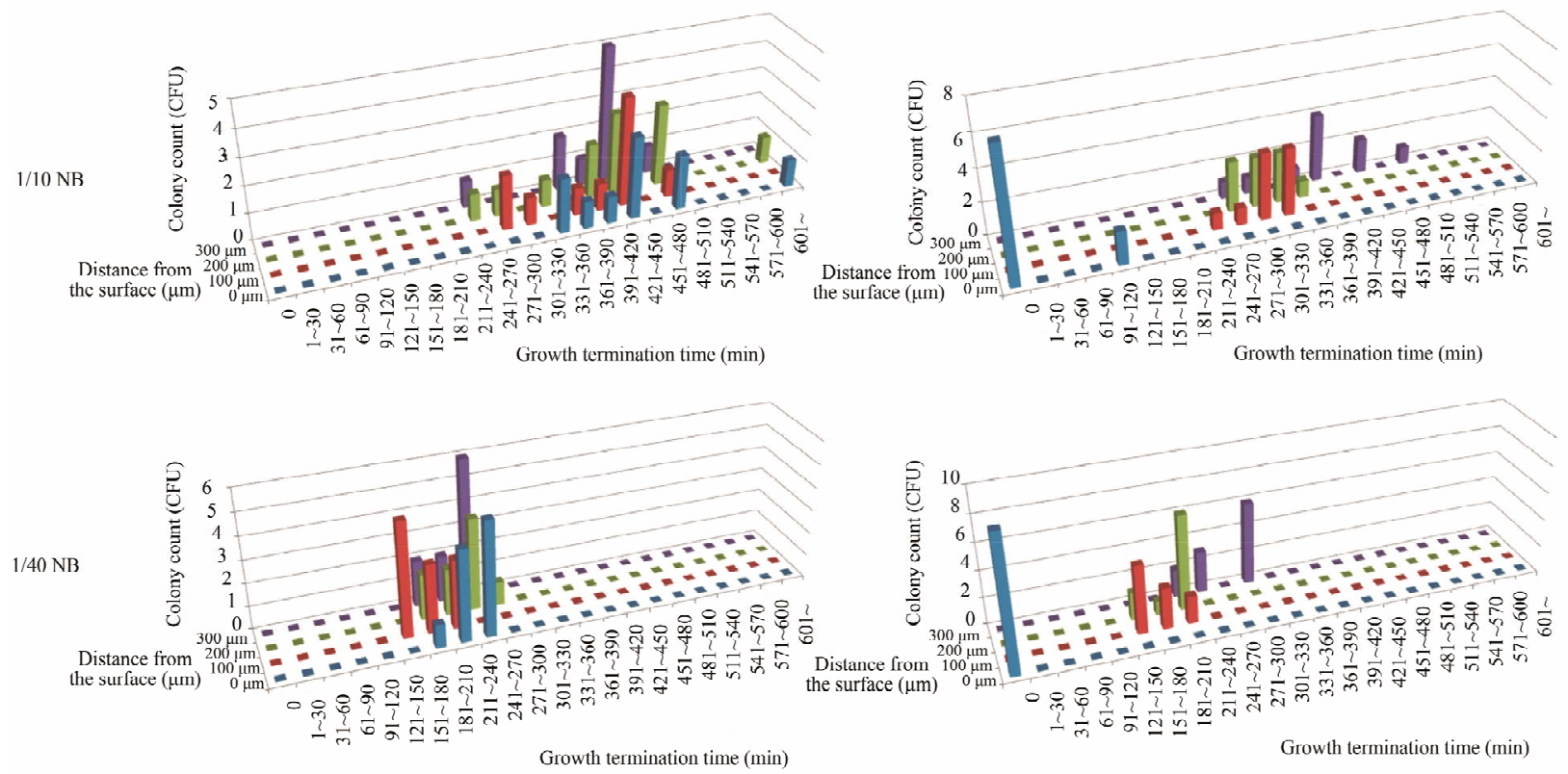

Figure S1. Distributions of growth termination times of E. coli at different distances from the antimicrobial (GPPS $1.0 \%)$ and non-antimicrobial (GPPS BL) surfaces in media of varying concentrations (from full-strength NB to 1/40 NB). 